\title{
İnvazif Enfeksiyonlara Neden Olan GSBL Pozitif Enterobacteriaceae İzolatlarında Karbapenem Direnci*
}

\section{Carbapenem Resistance in ESBL Positive Enterobacteriaceae Isolates Causing Invasive Infections}

\author{
Özgen KÖSEOĞLU ESER ${ }^{1}$, Hatice ALTUN ULUDAĞ ${ }^{1,2}$, Alper ERGIN³ ${ }^{3}$ Barış BORAL ${ }^{1}$, \\ Burçin ŞENER ${ }^{1}$, Gülşen HASÇELIK ${ }^{1}$

\footnotetext{
${ }^{1}$ Hacettepe Üniversitesi Tıp Fakültesi, Tıbbi Mikrobiyoloji Anabilim Dalı, Ankara.

${ }^{1}$ Hacettepe University Faculty of Medicine, Department of Medical Microbiology, Ankara, Turkey.

${ }^{2}$ Turgut Özal Üniversitesi Tıp Fakültesi, Tıbbi Mikrobiyoloji Anabilim Dalı, Ankara.

${ }^{2}$ Turgut Ozal University Faculty of Medicine, Department of Medical Microbiology, Ankara, Turkey.

${ }^{3}$ Hacettepe Üniversitesi Sağlık Hizmetleri Meslek Yüksekokulu, Tıbbi Laboratuvar Programı, Ankara.
} \\ ${ }^{3}$ Hacettepe University School of Health Services, Medical Laboratory Programme, Ankara, Turkey.
}

\section{ÖZET}

Bu çalışmada 2005-2009 yılları arasında Hacettepe Üniversitesi Hastanesinde invazif enfeksiyonlardan izole edilen Enterobacteriaceae türlerinde karbapenem direnç varlığının fenotipik ve genotipik olarak gösterilmesi amaçlanmıştır. Çalışmaya, BD Phoenix (Sparks, ABD) sistemiyle geniş spektrumlu beta-laktamaz (GSBL) pozitif olarak tespit edilen 153'ü Escherichia coli, 47'si Klebsiella pneumoniae, 10'u Klebsiella oxytoca olmak üzere toplam 210 kan izolatı dahil edilmiştir. İzolatların imipenem, meropenem ve ertapeneme karşı duyarlııkları, CLSI (Clinical Laboratory Standards Institute) önerilerine uygun şekilde mikrodilüsyon yöntemiyle, doripenem duyarlıı̆̆ı ise E-test (bioMerieux, Hazelwood, ABD) yöntemiyle araştırılmıştır. Çalışmada karbapeneme dirençli olarak tespit edilen izolatlarda fenotipik doğrulama testleri uygulanmış ve polimeraz zincir reaksiyonu (PCR) yöntemiyle $b l a_{\mathrm{AmpC}^{\prime}} b l a_{\mathrm{CTX}-\mathrm{M}^{\prime}} b l a_{\mathrm{KPC}^{\prime}} b l a_{\mathrm{NDM}^{\prime}} b l a_{\mathrm{OXA}^{\prime}} b l a_{\mathrm{IMP}}$ ve $b l a_{\mathrm{VIM}}$ antibiyotik direnç genlerinin varlığı araştıııımışıı. Çalışmamızda, GSBL üreten 210 Enterobacteriaceae kan izolatının 23 (\%11)'ünde karbapenem direnci saptanmış; imipenem, meropenem ve ertapenem direnci sırasıyla \%5.7 ( $n=12), \% 1.9(n=4)$ ve \%2.4 $(n=5)$ olarak belirlenmiştir. İzolatlara karşı en etkin karbapenem grubu antibiyotiğin doripenem (direnç \%1) olduğu gözlenmiştir. Yirmi üç izolatın yedisi sefotaksim/klavulanik asit (CTX/CLA) ve seftazidim/klavulanik asit (CAZ/CLA) kombine disk difüzyon 
yöntemiyle GSBL negatif bulunurken, CTX/CLA diskine boronik asit (BA) ilavesiyle yapılan modifiye kombine disk difüzyon yönteminde altı izolatın GSBL pozitif olduğu tespit edilmiştir. Modifiye Hodge testi (MHT) ve/veya ertapenem-BA kombine disk difüzyon testleriyle pozitif olarak saptanan üç izolatın birinde bla $a_{\mathrm{OXA}-48^{\prime}}$ diğerinde $b / a_{\mathrm{AmpC}}$ geni saptanmıştır. Fenotipik olarak pAmpC varlığı tespit edilen üç K.pneumoniae izolatının birinde bla ${ }_{\mathrm{AmpC}}$ geni gösterilmiştir. Bütün antibiyotikler için Mik değeri $256 \mu \mathrm{g} /$ $\mathrm{ml}$ olan ve meropenem-BA, MHT, imipenem-EDTA, seftazidim-CAZ/CLA, sefoksitin-BA pozitif olan bir K.pneumoniae izolatında bla $a_{\mathrm{OXA}-48}$ gen varlığı saptanmıştır. Beş izolatta bla $a_{\mathrm{OXA}-1}$ ve bir izolatta bla ${ }_{\mathrm{OXA}-10}$ gen varlığı gösterilmiştir. Iki izolat bla ${ }_{\mathrm{CTX}-\mathrm{M}}$ pozitif olarak bulunmuş; izolatların hiçbirinde bla $a_{\mathrm{IMP}}$ bla $a_{\mathrm{VIM}}$ ve bla ${ }_{\text {NDM-1 }}$ genleri tespit edilmemiştir. Sonuç olarak, dört yıllık sürede izole edilen invazif Enterobacteriaceae türlerinin karbapenemlere olan direnç değerleri düşük düzeyde bulunmuştur. İzolatlardaki direnç, genellikle bla $a_{\mathrm{OXA}}$ tipi karbapenemazlara bağlıdır ve bu izolatlarda bla ${ }_{\mathrm{KPC}}$ ve $b / a_{\mathrm{NDM}}$ varlığı saptanmamıştır.

Anahtar sözcükler: Enterobacteriaceae; GSBL; karbapenem direnci; karbapenemaz.

\section{ABSTRACT}

The aim of this study was to investigate the presence of carbapenem resistance in Enterobacteriaeceae isolates recovered from invasive infections, in Hacettepe University Hospital, Ankara, Turkey, between 2005-2009, by phenotypic and genotypic methods. A total of 210 non-duplicated Escherichia coli $(\mathrm{n}=$ 153), Klebsiella pneumoniae $(n=47)$ and Klebsiella oxytoca $(n=10)$ isolates which were all determined to be extended-spectrum beta-lactamase (ESBL) positive with the BD Phoenix automated identification and antibiotic susceptibility system (Sparks, USA), were included in the study. The isolates were recovered from patients with bloodstream infections. Susceptibility of the isolates to imipenem, meropenem and ertapenem was detected with microdilution method according to the standards of Clinical and Laboratory Standards Institute (CLSI) minimal inhibitory concentration (MIC) breakpoints. Doripenem susceptibility was detected by the E-test (bioMerieux, Hazelwood, USA). All isolates which were found to be non-susceptible to any of the carbapenem antibiotics tested, were characterized by the phenotypic

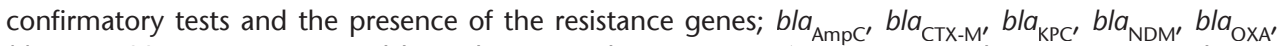
bla $_{\mathrm{IMP}}$ ve bla $\mathrm{VIM}_{\mathrm{V}}$ were screened by polymerase chain reaction (PCR). Among the 210 ESBL-producing Enterobacteriaceae blood isolates, $23(11 \%)$ were identified as non-susceptible to any of the carbapenems tested. Resistance rates for imipenem, meropenem and ertapenem were $5.7 \%(n=12), 1.9 \%$ $(n=4)$ and $2.4 \%(n=5)$, respectively. Doripenem was more active than the other carbapenems, with a resistance rate of $1.0 \%$. Seven of 23 isolates were ESBL negative with cefotaxime/clavulanic acid (CTX/ CLA) and ceftazidime/clavulanic acid (CAZ/CLA) combined disk diffusion test, however, six of them were ESBL positive with the addition of boronic acid (BA) to CTX/CLA. Among the three isolates positive for Modifiye Hodge test (MHT) and/or ertapenem-BA tests, bla $a_{\text {OXA-48 }}$ was detected in one and bla ${ }_{\mathrm{AmpC}}$ in the other. Phenotypic pAmpC activity was present in three K.pneumoniae isolates of which one was positive for bla $a_{\text {mpC }}$ gene. One K.pneumoniae isolate resistant to all carbapenems with MICs > $256 \mu \mathrm{g} /$ $\mathrm{ml}$ and positive for phenotypic meropenem-BA, MHT, imipenem-EDTA, ceftazidime-CAZ/CLA, cefoxitinBA production, was found to inhabit bla $a_{\mathrm{OXA}-48}$ gene. Five isolates were positive for bla $a_{\mathrm{OXA}-1}$ and one for $b / a_{\mathrm{OXA}-10}$. Two isolates were positive for bla ${ }_{\mathrm{CTX}-\mathrm{M}^{\prime}}$ however $b / a_{\mathrm{IMP}} b / a_{\mathrm{VIM}}$ and $b / a_{\mathrm{NDM}-1}$ genes were not detected among the isolates. In conclusion, carbapenem non-susceptibility which was low among the Enterobacteriaceae strains isolated in our center, was mostly attributed to the presence of bla $a_{\text {OXA }}$ type carbapenemases and no accumulation of $b / a_{\mathrm{KPC}}$ and $b / a_{\mathrm{NDM}}$ were detected.

Key words: Enterobacteriaceae; ESBL; carbapenem resistance; carbapenemase. 


\section{Giriş}

Enterobacteriaceae ailesinde yer alan Escherichia coli ve Klebsiella pneumoniae, toplum ve hastane kaynaklı enfeksiyonlara neden olan bakterilerdir. Bu bakterilerde dirençten sorumlu en önemli mekanizma genişlemiş spektrumlu beta-laktamaz (GSBL) yapımıdır. Karbapenemler, GSBL üreten, özellikle çok ilaca dirençli Enterobacteriaceae türlerinde, son seçenek olarak kullanılan önemli bir antibiyotik grubudur. Karbapenemaz üreten izolatlar, ciddi enfeksiyonlara neden olarak hastanede yatış süresini uzatmakta ve mortalite oranlarını artırmaktadır. Dolaısıyla karbapenemlere karşı gelişen direncin izlenmesi önem taşımaktadır ${ }^{1}$.

Karbapenem direnci çeşitli mekanizmalarla oluşmaktadır. Karbapenemleri hidroliz eden üç farklı sınıf beta-laktamaz bulunmaktadır. Bunlar Ambler sınıf A, sınıf B (metallobeta-laktamazlar) ve sınıf D (oksasilinazlar) beta-laktamazlardır. Karbapenem direnci, bakteride plazmid aracılı AmpC (pAmpC) beta-laktamazlarla birlikte, porin mutasyonlarına bağlı dış membran geçirgenliğinin azalması sonucunda da ortaya çıkmaktadır².

Karbapenemaz üreten Enterobacteriaceae türlerinin tanısında, 2010 yılından önce "Clinical and Laboratory Standards Institute (CLSI)" antibiyotik sınır değerlerine göre imipenem, meropenem ve ertapenem için $\geq 2 \mu \mathrm{g} / \mathrm{ml}$ minimum inhibitör konsantrasyonu (MiK) değerlerinin belirlenmesi durumunda, fenotipik ve/veya genotipik ileri testlerin yapılması önerilmiştir ${ }^{3}$. Bu açıdan modifiye Hodge testi (MHT), CLSI tarafından karbapenemaz doğrulama testi olarak önerilen tek fenotipik test olmuştur. 2010 yılı öncesi CLSI rehberlerine göre, karbapenem direnci açısından şüpheli Enterobacteriaceae izolatlarında MHT'nin pozitif bulunması halinde, yapılan mikrodilüsyon testi sonucunda ertapenem Mik değeri 2-4 $\mu \mathrm{g} / \mathrm{ml}$, imipenem 2-8 $\mu \mathrm{g} / \mathrm{ml}$ ve meropenem $2-8 \mu \mathrm{g} / \mathrm{ml}$ bulunursa izolatların tüm karbapenemlere dirençli olarak rapor edilmesi önerilmiştir. Ancak CLSI'nın 2010 yılında mikrodilüsyon duyarlılık sınır değerlerinde yaptığı değişiklik sonucunda, imipenem, meropenem, doripenem için duyarlılık sınır değerleri $\leq 1 \mu \mathrm{g} / \mathrm{ml}$, ertapenem için ise $\leq 0.5 \mu \mathrm{g} / \mathrm{ml}$ şeklinde belirlenmiştir. CLSI, yeni düşük sınır değerlerinin uygulanması durumunda, MHT'nin sadece enfeksiyon kontrol ve epidemiyolojik amaçlı yapılmasını ve karbapenem duyarlılık test sonuçlarının değiştirilmeden bildirilmesini önermiştir ${ }^{4}$.

MHT'nin tek başına karbapenemaz tanımlama testi olarak kullanımı doğru bir yaklaşım değildir. Bu nedenle, karbapenemazları tanımlamada kullanılacak etkin fenotipik testlere gereksinim vardır. MHT dışında, karbapenemazların saptanmasında halen çift disk sinerji ve kombine disk difüzyon testleri kullanılmaktadır. MBL üreten izolatların belirlenmesinde EDTA'nın indirgenmesi temeline dayanan fenotipik testlerin yanı sıra, boronik asit (BA)'in kullanıldığı çift disk veya kombine disk difüzyon testleriyle KPC tipi beta-laktamazların tanımlanmasında kullanılan testler de bulunmaktadır ${ }^{5}$. Karbapenemazlara ait bla genlerinin genotipik olarak polimeraz zincir reaksiyonu (PCR) ile gösterilmesi laboratuvar tanısında altın standarttır.

Karbapenemaz üreten Enterobacteriaceae izolatlarının hızlı saptanması veya yayılımının engellenmesi açısından, karbapenem MiK değerlerinin düşürülmesi anlam ifade etse de, bu yaklaşım yanlış pozitif sonuçların artmasına yol açmaktadır. Bu enfeksiyonların hastane ortamındaki gerçek oranlarının belirlenmesi, uygun antibiyotik kullanımı ve enfeksiyon kontrolü açısından önem taşımaktadır. Bu çalışmada 2005-2009 yılları ara- 
sında Hacettepe Üniversitesi Erişkin Hastanesinde invazif enfeksiyon tanısıyla takip edilen hastalardan izole edilen Enterobacteriaceae türlerinde karbapenem direnç varlığının fenotipik ve genotipik olarak gösterilmesi amaçlanmıştır.

\section{GEREÇ ve YÖNTEM}

\section{Bakteriyel İzolatlar ve Antibiyotik Duyarlılık Testleri}

Çalışmaya, 2005-2009 yılları arasında BD Phoenix (BD, Sparks, ABD) otomatize bakteri tanımlama ve antibiyotik duyarlılık sistemiyle GSBL pozitif olarak tespit edilen 210 izolat (153 E.coli, 47 K.pneumoniae ve 10 K.oxytoca) dahil edildi. Invazif enfeksiyon tanısı alan hastaların kan kültürlerinden izole edilen tek bir suş çalışmaya alındı. İzolatlar konvansiyonel yöntemlerle doğrulandı. İzolatların imipenem, meropenem ve ertapenem antibiyotik duyarlııkları, CLSı önerileri doğrultusunda mikrodilüsyon yöntemiyle, doripenem duyarlılığı ise E-test (bioMerieux, Hazelwood, ABD) yöntemiyle araştırıldı. Duyarlılık sonuçları CLSI, MiK sınır değerlerine göre belirlendi ${ }^{3}$. Tüm testlerde kontrol amacıyla E.coli ATCC 25922 standart suşu kullanıldı.

Karbapeneme dirençli izolat tespit edilen hastaların, yaş, cinsiyet, yoğun bakım ünitelerinde yatış durumu, altta yatan hastalıkları, verilen antibiyotik tedavisi ve son sağlık durumları hasta kayıt sisteminden elde edildi.

\section{GSBL Tanısının Doğrulanması}

CLSI tarafından önerilen sefotaksi-klavulanik asit (CTX-CLA) (Becton Dickinson, ABD) ve seftazidim-klavulanik asit (CAZ-CLA) (Becton Dickinson, ABD) kombine disk difüzyon doğrulama testinin yanı sıra, klavulanik asidin BA ile birlikte kullanıldığı modifiye kombine disk difüzyon yöntemi de kullanıldı ${ }^{4,5}$.

\section{Karbapenemazların Saptanması}

Karbapeneme dirençli olarak tespit edilen izolatlara fenotipik doğrulama testleri uygulandı. Bu amaçla MHT, CLSı kriterlerine göre çalışıldı ${ }^{3}$. KPC tipi karbapenemazların tespiti için ayrıca, meropenem(MER)/ meropenem-BA (Becton Dickinson, ABD) ve ertapenem (ETP)/ETP-BA (Becton Dickinson, ABD) kombinasyon disk yöntemleri kullanıldı ${ }^{4}$. Metallo-beta-laktamaz tanımlanması için, CLSI kriterlerine uygun olarak imipenem (IMP)/IMP-EDTA (Becton Dickinson, ABD) kombine disk difüzyon yöntemi kullanıldı ${ }^{4}$. AmpC beta-laktamaz üretiminin tespiti için, sefoksitin (FOX) (Becton Dickinson, $A B D$ )BA $(400 \mu g)$ kombine disk difüzyon testi uygulandı ${ }^{6}$.

\section{Genotipik Testler}

Karbapeneme dirençli olarak tespit edilen izolatlarda, dirençten sorumlu olabilecek gen varlığını göstermek amacıyla PCR yöntemi kullanıldı. İzolatların DNA'ları kaynatma yöntemiyle elde edildi. İzolatlarda bla $a_{\text {KPC }}$ gen varlığının araştırılması için $F$ (5'-TGTCACTGTATCGCCGTCTTAG-3') ve R (5'-TTACTGCCCGTTGACGCCCAATCC-3') primer dizileri ${ }^{1}$; bla ${ }_{\text {OXA }}$ gen bölgeleri için multipleks PCR yönteminde kullanılan $b l a_{\text {OXA-1 }}-\mathrm{F}$ (5'-CAGATTCAACTTTCA AGATCG-3') ve R (5'-GTGTTTAGAATGGTGATCG-3'); bla ${ }_{\text {OXA- }-2}$-F $^{-}$ (5'-AAGAAACGCTACTCGCCTGC-3') ve R (5'-CCACTCAACCCATCC TACCC-3'), bla ${ }_{\text {OXA- }}$ 
$10^{-\mathrm{F}}$ (5'-GTCTTTCGAGTACGGCATTA-3') ve R (5'-ATTTTCTTAGCGGCAACTTAC-3') primerleri ${ }^{7}$; bla $a_{\text {OXA-48 }}$ gen bölgesi için $F\left(5^{\prime}\right.$-GCGTGGTTAAGGATGAACAC-3') ve $R$ (5'-CATCAAGTTCAACCCAACCG-3') primerleri ${ }^{1}$ kullanıldı. MBL genleri için, bla ${ }_{ı \mathrm{MP}}-\mathrm{F}$ (5'-CTACCGTTTTGCCTTACCAT-3') ve R (5'-AACCAGTTTTGCCTTACCAT-3'); bla ${ }_{\mathrm{VIM}^{-}}{ }^{-\mathrm{F}}$ (5'-AGTGGTGAGTATCCGACAG-3') ve R (5'-ATGAAAGTGCCTGGAGAC-3'); bla ${ }_{\text {NDM- } 1^{-}}$(5'-GGTTTGGCGATCTGGTTTTC-3') ve R (5'-CGGAATGGCTCATCACGATC-3'); bla ${ }_{\text {СTX- }}$ $\mathrm{M}^{-\mathrm{F}}\left(5^{\prime}\right.$-TCTTCCAGAATAAGGAATCCC-3') ve R (5'-CCGTTTCCGCTATTACAAAC-3') primerleri kullanıldı ${ }^{1}$. pAmpC beta-laktamazların varlığının tespit edilmesi için bla ${ }_{A m p C}$ gen ailesinde yer alan altı gen ( $b / a_{\mathrm{MOX}}, b / a_{\mathrm{CIT}^{\prime}}, b / a_{\mathrm{DHA}^{\prime}} b / a_{\mathrm{ACC}}, b l a_{\mathrm{FOx}}$ ve $\left.b / a_{\mathrm{EBC}}\right)$ multipleks PCR yöntemi ile araştırıldı ${ }^{8}$.

\section{BULGULAR}

Çalışmamızda, GSBL üreten 210 Enterobacteriaceae izolatının 23 (\%11)'ünde karbapenem direnci saptanmıştır (Tablo I).

İmipenem MiK değerleri, meropenem, ertapenem ve doripenem MiK değerlerinden daha yüksek olarak saptanmıştır (Şekil 1, Tablo II). Yirmi üç izolatın hepsi imipeneme dirençli iken, 10'u ertapeneme, 9'u meropeneme ve 2'si doripeneme dirençli bulunmuştur. Karbapeneme dirençli 23 izolatın antibiyotiklere göre kümülatif MiK dağılımı Şekil 1'de gösterilmiştir. Buna göre doripenem, diğer karbapenemlerden daha etkili olarak gözlenmiştir. Ertapenem ve meropenem benzer etkinliğe sahipken, imipenem en düşük etkinliğe sahip karbapenem olarak belirlenmiştir.

\begin{tabular}{|lcccc|}
\hline \multicolumn{5}{l}{ Tablo I. GSBL Üreten Izolatların Karbapenem Duyarlılıları $(n=210)$} \\
\hline Antibiyotik & $\begin{array}{c}\text { MiK Aralığı } \\
(\mu \mathrm{l} / \mathrm{ml})\end{array}$ & $\begin{array}{c}\text { Mik }_{50} \\
(\mu \mathrm{l} / \mathrm{ml})\end{array}$ & $\begin{array}{c}\text { Mik }_{90} \\
(\mu \mathrm{ll} / \mathrm{ml})\end{array}$ & $\begin{array}{c}\text { Direnç } \\
\mathbf{n}(\%)\end{array}$ \\
\hline Imipenem & $0.25->256$ & 2 & 8 & $12(5.7)$ \\
Meropenem & $<0.125->256$ & 0.125 & 1 & $4(1.9)$ \\
Ertapenem & $<0.125->256$ & $<0.125$ & 0.25 & $5(2.4)$ \\
Doripenem & $0.008->256$ & 0.016 & 0.032 & $1(0.5)$ \\
\hline
\end{tabular}

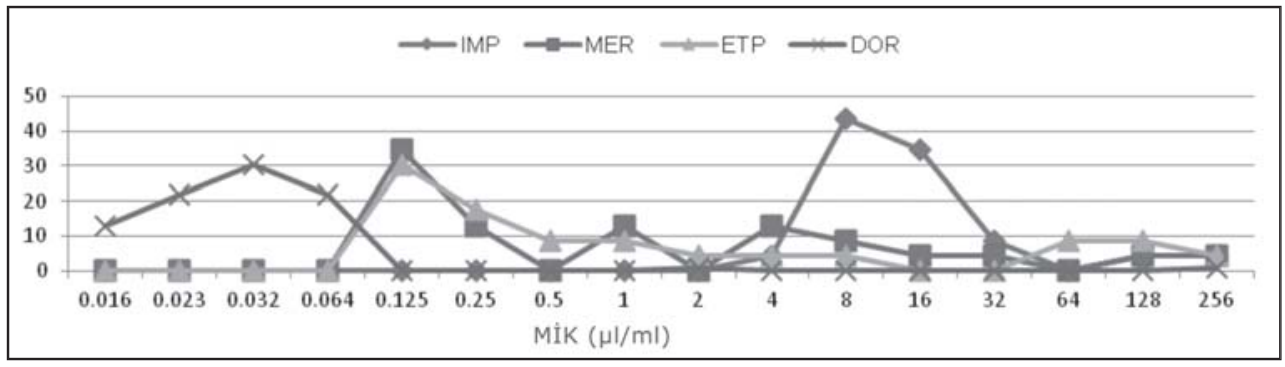

Şekil 1. Karbapeneme dirençli 23 izolatın kümülatif yüzdeleri (\%). 


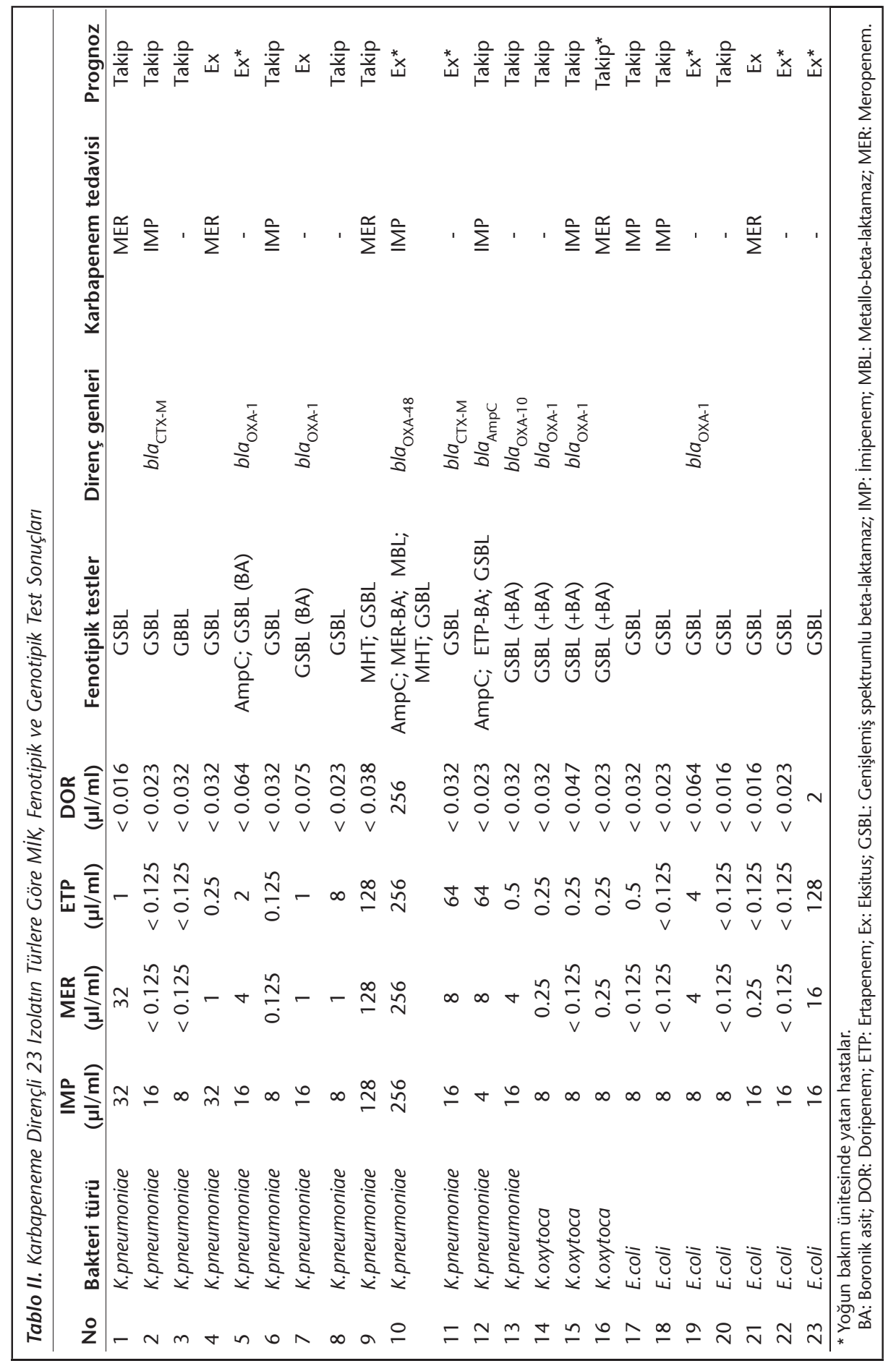


Yirmi üç izolatın 7'si CTX/CLA ve CAZ/CLA yöntemiyle GSBL negatif olarak bulunurken, CTX/CLA diskine BA eklenmesiyle bu izolatlardan 6'sının GSBL pozitif olduğu tespit edilmiştir. MHT ve/veya ETP-BA kombine disk difüzyon testleriyle pozitif olarak saptanan 3 izolatın birinde bla ${ }_{\mathrm{OXA}-48^{\prime}}$ diğerinde bla ${ }_{\mathrm{AmpC}}$ geni saptanmıştır (Tablo II).

Fenotipik olarak AmpC varlığı tespit edilen 3 K.pneumoniae izolatının birinde blaAmpC geni gösterilmiştir. Bu izolatların ikisinde aynı zamanda fenotipik olarak karbapenemaz varlığı tespit edilmiştir. Bütün antibiyotikler için MiK değeri $256 \mu \mathrm{g} / \mathrm{ml}$ olan ve MER-BA, MHT, IMP-EDTA, CAZ-CAZ/CLA, FOX-BA pozitif olan bir K.pneumoniae izolatında bla ${ }_{\mathrm{OXA}-48}$ gen varlığı bulunmuştur. Beş izolatta bla ${ }_{\mathrm{OXA}-1}$ ve bir izolatta bla ${ }_{\mathrm{OXA}-10}$ gen varlığı gösterilmiştir (Tablo II). İki izolatta ise bla $a_{\text {СТХ-M }}$ pozitif olarak bulunmuştur. İzolatların hiçbirinde $b l_{\mathrm{IMP}^{\prime}}$ bla $a_{\mathrm{VIM}}$ ve bla ${ }_{\mathrm{NDM}-1}$ genleri tespit edilmemiştir.

Karbapeneme dirençli suşların izole edildiği 23 hastanın özellikleri Tablo III'te görülmektedir. Yoğun bakım ünitelerinde yatan hasta sayısı 7 olarak belirlenmiş, bütün hastalarda altta yatan hastalıkların olduğu saptanmıştır. Hastaların 12'sine enfeksiyon tedavileri sırasında imipenem veya meropenem verilmiştir.

\section{TARTIŞMA}

2000'li yıllardan itibaren karbapenemler dışında tüm sefalosporinlere dirençli kabul edilen GSBL üreten E.coli izolatlarının dünyada yaygınlaşması sonucu hayatı tehdit eden nozokomiyal enfeksiyonlarının tedavisinde son seçenek ilaç olarak karbapenemlerin korunması gerekliliği öne çıkmıştır. Gelecekte dünyada karbapenem üreten mikroorganizmalar ile iki büyük epidemi beklenmekte; bunlardan birinin toplum kaynaklı E.coli suşları, diğerinin ise hastane kaynaklı K.pneumoniae suşları ile gerçekleşmesi öngörülmektedir $^{1}$. Bu nedenle, karbapenem üreten mikroorganizmaların erken tanımlanması hastane salgınlarının önlenmesi açısından zorunludur.

\begin{tabular}{|lc|}
\hline Tablo III. Karbapeneme Dirençli Suşların İzole Edildiği Hastaların Özellikleri $(n=23)$ \\
\hline Yaş ortalaması (Yaş aralığı) (Yıl) & $50(0-75)$ \\
Kadın/Erkek (n) & $13 / 10$ \\
Yoğun bakım/Servis (n) & $7 / 16$ \\
IMP \& MER tedavisi alan hasta sayısı & 12 \\
Altta yatan hastalık varlığı (n) & \\
$\quad$ Kanser* & 13 \\
$\quad$ Diğer** & 10 \\
Prognoz & 14 \\
$\quad$ Takip & 9 \\
$\quad$ Ölüm & \\
\hline * Lenfoma, pankreas, prostat, over, mide, böbrek hücre, sarkoma, Hodgkin. \\
** Kronik hepatit/karaciğer, talamik kanama, tüberküloz menenjiti, Hashimoto tiroidi, Guillain Barre, polihidroamni- \\
$\quad$ yozis, kanamalı üremik sendrom. \\
\hline
\end{tabular}


Amerika Birleşik Devletleri (ABD)'nde 2007-2009 yılları arasında SENTRY çalışması kapsamında 42 merkezden toplanan hastane enfeksiyonu etkeni 2049 K.pneumoniae izolatında karbapenem direnci \%6.1 olarak tespit edilmiştir ${ }^{9}$. COMPACT çalışması kapsamında Türkiye'den dahil edilen 10 merkezden 2008 yılı içinde toplanan 240 Enterobacteriaceae izolatında doripenem, imipenem ve meropenem direnç oranları \%1.3 olarak saptanırken, doripenem ve meropenem $0.12 \mu \mathrm{g} / \mathrm{ml}$ MiK $_{90}$ değeri ile imipenemden $\left(\right.$ MiK $_{90}=0.5 \mu \mathrm{g} / \mathrm{ml}$ ) dört kat daha aktif bulunmuştur ${ }^{10}$. Çalışmamızda Enterobacteriaceae türlerinde imipenem, meropenem ve ertapeneme düşük düzeyde direnç (sırasıyla; \%5.7, \%1.9 ve \%2.4) saptanmıştır. Doripenem ise en etkili karbapenem olarak belirlenmiştir. Doripenemin, Enterobacteriaceae türlerinde daha duyarlı olduğu diğer bazı çalışmalarla da desteklenmiştir ${ }^{11,12}$. COMPACT çalışmasının Almanya'da yedi merkezden toplanan 167 Enterobacteriaceae izolatında MiK $_{90}$ değerleri, doripenem, meropenem ve imipenem için sırasıyla $0.06,0.06$ ve $0.5 \mu \mathrm{g} / \mathrm{ml}$ olarak belirlenirken, Asya-Pasifik bölgesine ait beş ülkede COMPACT çalışmasına dahil olan 20 merkezden toplanan 500 Enterobacteriaceae izolatında Mik $_{90}$ sonuçları sırasıyla $0.09,0.09$ ve 0.5 $\mu \mathrm{g} / \mathrm{ml}$ olarak tespit edilmiştir ${ }^{11,12}$.

Enterobacteriaceae izolatlarında bulunan pAmpC türü beta-laktamazların GSBL'leri maskeleyerek saptanmalarını önledikleri çeşitli çalışmalarda gösterilmiştir ${ }^{13}$. Baykal ve arkadaşlarının ${ }^{14}$ yaptıkları bir çalışmada, 99 E.coli ve 114 K.pneumoniae izolatının 10'unda pAmpC pozitifliği GSBL ile birlikte tespit edilmiş ve bir izolatta GSBL fenotipinin maskelenmiş olduğu bulunmuştur. Çalışmamızda, otomatize yöntemle GSBL pozitif sonuç veren izolatlar içinde karbapenem direnci belirlenen 23 izolatın sadece 17'sinde CTXCLA ve CAZ-CLA kombine disk difüzyon doğrulama testleriyle GSBL pozitif bulunmuş, ancak BA ilavesiyle geriye kalan altı izolatta da GSBL üretimi doğrulanmıştır. pAmpC varlığı FOX-BA kombine disk difüzyon yöntemiyle araştırılmış ve üç izolatta fenotipik olarak pAmpC varlığı gözlenirken, bunların birinde bla $a_{A m p C}$ geni tespit edilmiştir. Karbapenem direncinin rutin mikrobiyoloji laboratuvarında belirlenmesi önemlidir. 2010 yılında değişen CLSI sınır değerleri, düşük karbapenem MiK değerlerine sahip karbapenemaz üreten izolatların gözden kaçmasına neden olabildiği gibi, bu izolatların karbapenemaz pozitif olarak değerlendirilip karbapenem tedavisinden gereksiz yere kaçınılmasına da yol açabilmektedir. Karbapenemazları belirlemede kullanılan MHT'nin yüksek duyarlılığına rağmen, bu test özellikle GSBL veya azalmış porinler ile birlikte pAmpC varlığı halinde yanlış pozitif sonuçlar verebilmektedir. Bu nedenle, karbapenemaz üreten Enterobacteriaceae izolatlarının saptanmasında doğrulama testlerinin uygulanmasının önemi büyüktür ${ }^{15}$. Düşük özgüllüğe sahip olması nedeniyle $\mathrm{MHT}^{\prime}$ ni yorumlarken olası yanlış pozitif sonuçları göz önünde bulundurmak gerekmektedir ${ }^{16}$. Çalışmamızda karbapenemaz geni pozitif yedi izolattan sadece birinde MHT pozitif sonuç vermiştir. MHT'nin yanlış pozitif ve/veya negatif sonuç vermesi, izolatlardaki diğer bla ${ }_{\mathrm{CSBL}}$ veya bla ${ }_{\mathrm{AmpC}}$ gen varlıklarına bağlanmaktadır. Bu açıdan değerlendirme yapıldığında, bla ${ }_{\mathrm{AmpC}}$ gen pozitifliği bir izolatta, fenotipik pAmpC varlığı üç izolatta tespit edilmiştir. İzolatların hepsinin GSBL pozitif oldukları göz önüne alındığında, karbapenemaz varlığı gösterilemeyen izolatlarda, başka antibiyotik direnç mekanizmalarının olduğu düşünülmelidir. Buna benzer nedenlerle, laboratuvarlarda karbapenemazların tanısında tercih edilen fenotipik testlerin, doğru tanıya götürecek yeni modifikasyonlarının takip edilerek kullanılması önem taşımaktadır. 
Enterobacteriaceae türlerinde görülen karbapenem direncinden en sık sorumlu mekanizma, karbapenemaz enzimlerinin üretimi olmakla birlikte, eş zamanlı gelişen porin kaybı veya atım pompası aktivitesindeki artış da direncin ortaya çıkışını kolaylaştırmaktadır $^{17}$. Yapılan çalışmalarda, özellikle bla $a_{\mathrm{KPC}}$ pozitif olan K.pneumoniae izolatlarında karbapenem direnci, porin mutasyonlarına bağlı olarak gelişebilmektedir. Kültür pasajları ve izolatların stoklanması sırasında gelişen gen kayıpları, dirençli izolatların stoklanma sonrasında duyarlı hale geçebildiğini göstermiştir ${ }^{17}$. Direnç belirlenen izolatlar içerisinde yedi izolatta karbapenemaz gen varlığı gösterilse de, izolatlardaki karbapenem direnci çok farklı nedenlere bağlı olabilmektedir. Bu direncin GSBL veya AmpC tipi enzimlerle birlikte bakteride bulunan porin kaybı veya artmış atım pompa aktivitesi nedeniyle de gelişebileceği düşünülmelidir ${ }^{15,18,19}$. Ayrıca, yüksek MiK değerlerinin sebebi, bu çalışmada araştırılmayan diğer direnç genlerinin varlığıyla da açıklanabilir.

K.pneumoniae' da bla ${ }_{\text {OXA-48 }}$ varlığı ilk defa 2001 yılında Türkiye'deki bir izolatta bildirilmiştir $^{20}$. OXA-48 üreten K.pneumoniae izolatları Türkiye'yi takiben Orta Doğu, Kuzey Afrika, Avrupa ve Amerika'dan da bildirilmiştir ${ }^{21}$. Son birkaç yıl içinde Avrupa'da karbapenemaz üreten izolatlara bağlı enfeksiyonlardaki artış, özellikle OXA-48'in toplum kaynaklı yayılımına bağlanmaktadır ${ }^{22}$. Çalışmamızda, K.pneumoniae izolatlarından birinde bla ${ }_{\mathrm{OXA}-48}$ gen varlığı saptanmış olup, bu izolat bütün karbapenemler için çok yüksek düzey direnci gösteren MiK değerine (256 mg/L) sahiptir. Kullanılan birçok fenotipik test bu izolat açısından pozitif sonuç vermiştir (Tablo II). İzolat yoğun bakım ünitesinde yatan akut miyelositer lösemili bir hastadan elde edilmiş ve hasta tedavisi sırasında imipenem de dahil olmak üzere birçok beta-laktam kullanmasına rağmen hayatını kaybetmiştir.

Yapılan çalışmalar, E.coli ve K.pneumoniae'ya bağlı septisemi olgularında karbapenemaz varlığının, hastanın morbidite ve mortalitesini artıran sonuçlara neden olduğunu ve bu tip izolatlarda GSBL ve karbapenemazların birlikte bulunmasının, hasta ölüm oranlarını daha da yükselttiğini göstermektedir ${ }^{23}$. Karbapenem direnci belirlenen izolatların elde edildiği hastalar hakkındaki bilgilerimiz kısıtlı olmakla birlikte, izolatların hepsinin kan örneği olması, hasta yaş ortalamasının yüksek olması, hastaların tümünde altta yatan hastalıkların bulunması ve yarıdan fazlasının tedavileri sırasında imipenem ve/veya meropenem alma öyküsünün bulunması, karbapenemaz varlığı açısından izolatların değerlendirilmesi gereğini ortaya koymuştur. Karbapenemaz gen varlığı gösterilen yedi izolat, aynı zamanda GSBL pozitif olarak belirlenirken, hastalarda ölüm oranı \%39 (9/23) olarak izlenmiştir. Dolayısıyla karbapenemazların tanı ve takibinin, tedavi ve prognoz açısından önemi bu çalışmayla da desteklenmiştir.

Sonuç olarak, 2005-2009 yılları arasında hastanemizde invazif enfeksiyonlardan izole edilen Enterobacteriaceae türlerinde karbapenem direnç değerlerinin düşük olduğu ve direncin sıklıkla bla ${ }_{\mathrm{OXA}}$ tipi karbapenemazlara bağlı olduğu görülmüştür. İzolatlarda $b / a_{\mathrm{KPC}}$ ve bla ${ }_{\mathrm{NDM}}$ varlığı saptanmamıştır. Karbapenem direncinin yorumlanmasında uygulanmaya başlanan yeni CLSI MiK sınır değerleri, rutin mikrobiyoloji laboratuvarlarında, karbapenemaz üretimine bakmaksızın, karbapenem direnci bildirilmesine neden olmaktadır. Ancak, birçok Enterobacteriaceae izolatında karbapenemaz aktivitesi gös- 
teren enzimler olmadığı halde, karbapenem Mik değerleri yüksek bulunabilmektedir. Bu durum, birçok antibiyotik grubunun tedavide kullanılabilirliğini kısıtlamaktadır ${ }^{24}$. Bu nedenle, hastane ortamında enfeksiyon kontrol politikalarının doğru uygulanabilmesi için, karbapenemazları saptayan güvenilir ve basit testlere gereksinim vardır. Bu araştırma, hastanemizde henüz tehdit edici boyuta varmamış olan düşük karbapenem direncini saptaması ve bu dirence sahip izolatlarda direnç mekanizmalarını analiz etmesi nedeniyle, daha sonra yapılacak çok merkezli araştırmalara ışık tutacaktır.

\section{TEŞEKKÜR}

Pozitif kontrol suşları için Prof. Dr. Murat Akova (Hacettepe Üniversitesi Tıp Fakültesi), Prof. Dr. Rıza Durmaz (Türkiye Halk Sağlığı Kurumu) ve Dr. Thierry Nass (Paris-Sud Üniversitesi Tıp Fakültesi)'a teşekkür ederiz.

\section{KAYNAKLAR}

1. Nordmann P, Naas T, Poirel L. Global spread of carbapenemase-producing Enterobacteriaceae. Emerg Infect Dis $2011 ; 17(10): 1791-8$.

2. Miriagou V, Cornaglia G, Edelstein $M$, et al. Acquired carbapenemases in gram-negative bacterial pathogens: detection and surveillance issues. Clin Microbiol Infect 2010; 16(2): 112-22.

3. Clinical and Laboratory Standards Institute. Performance standards for antimicrobial susceptibility testing. $22^{\text {nd }}$ Informational Supplement. CLSI Document M100-S19, 2009. CLSI, Wayne, PA.

4. Clinical and Laboratory Standards Institute. Performance standards for antimicrobial susceptibility testing. $22^{\text {nd }}$ Informational Supplement. CLSI Document M100-S22, 2012. CLSI, Wayne, PA.

5. Tsakris A, Poulou A, Pournaras S, et al. A simple phenotypic method for the differentiation of metallo-betalactamases and class A KPC carbapenemases in Enterobacteriaceae clinical isolates. J Antimicrob Chemother 2010; 65(8): 1664-71.

6. Song W, Bae IK, Lee YN, Lee CH, Lee SH, Jeong SH. Detection of extended-spectrum beta-lactamases by using boronic acid as an AmpC-lactamase inhibitor in clinical isolates of Klebsiella spp. and Escherichia coli. J Clin Microbiol 2007; 45(4): 1180-4.

7. Costa D, Poeta P, Saenz Y, et al. Prevalence of antimicrobial resistance and resistance genes in faecal Escherichia coli isolates recovered from healthy pets. Vet Microbiol 2008; 127(1-2): 97-105.

8. Perez-Perez FJ, Hanson ND. Detection of plasmid-mediated AmpC beta-lactamase genes in clinical isolates by using multiplex PCR. J Clin Microbiol 2002; 40(6): 2153-62.

9. Kaiser DM, Castanheira M, Jones RN, Tenover F, Lynfield R. Trends in Klebsiella pneumoniae carbapenemasepositive K.pneumoniae in US hospitals: report from the 2007-2009 SENTRY Antimicrobial Surveillance Program. Diagn Microbiol Infect Dis 2013; 76(3): 356-60.

10. Leblebicioğlu H, Cakir N, Celen M, Kurt H, Baris H, Laeuffer J; Turkish COMPACT Study Group. Comparative activity of carbapenem testing (the COMPACT study) in Turkey. BMC Infect Dis 2012; 12: 42.

11. Valenza G, Seifert H, Decker-Burgard S, Laeuffer J, Morrissey I, Mutters R. Comparative activity of carbapenem testing (COMPACT) study in Germany. Int J Antimicrob Agents 2012; 39(3): 255-8.

12. Kiratisin $\mathrm{P}$, Chongthaleong $\mathrm{A}$, Tan TY, et al. Comparative in vitro activity of carbapenems against major gram-negative pathogens: results of Asia-Pacific surveillance from the COMPACT II study. Int I Antimicrob Agents 2012; 39(4): 311-6.

13. Jacoby GA. AmpC beta-lactamases. Clin Microbiol Rev 2009; 22(1): 161-82.

14. Baykal A, Çöplü N, Şimşek H, Esen B, Gür D. Kan izolatı E.coli ve K.pneumoniae suşlarında genişlemişspektrumlu beta-laktamaz, KPC-tip karbapenemaz ve plazmid aracılı AmpC beta-laktamaz varlığının araştııılması. Mikrobiyol Bul 2012; 46(2): 159-69. 
15. Birgy A, Bidet $P$, Genel N, et al. Phenotypic screening of carbapenemases and associated beta-lactamase in carbapenem-resistant Enterobacteriaceae. J Clin Microbiol 2012; 50(4): 1295-302.

16. Girlich D, Poirel L, Nordmann P. Value of the modified Hodge test for detection of emerging carbapenemases in Enterobacteriaceae. J Clin Microbiol 2012; 50(2): 477-9.

17. Gomez E, Urban C, Mariano N, et al. Phenotypic and genotypic screening and clonal analysis of carbapenem-resistant Klebsiella pneumoniae at a single hospital. Microb Drug Resist 2011; 17(2): 251-7.

18. Doumith M, Ellington MJ, Livermore DM, Woodford N. Molecular mechanisms disrupting porin expression in ertapenem-resistant Klebsiella and Enterobacter spp. clinical isolates from the UK. J Antimicrob Chemother 2009; 63(4): 659-67.

19. Baroud M, Dandache I, Araj GF, et al. Underlying mechanisms of carbapenem resistance in extended-spectrum beta-lactamase-producing Klebsiella pneumoniae and Escherichia coli isolates at a tertiary care centre in Lebanon: role of OXA-48 and NDM-1 carbapenemases. Int J Antimicrob Agents 2013; 41(1): 75-9.

20. Poirel L, Heritier C, Tolün V, Nordmann P. Emergence of oxacillinase-mediated resistance to imipenem in Klebsiella pneumoniae. Antimicrob Agents Chemother 2004; 48(1): 15-22.

21. Patel A, Bonomo RA. Stormy waters ahead: global emergence of carbapenemases. Front Microbiol 2013; 4: 48.

22. Canton R, Akova M, Carmelli Y, et al. Rapid evolution and spread of carbapenemases among Enterobacteriaceae in Europe. Clin Microbiol Infect 2012; 18(5): 413-31.

23. Gupta V, Bansal N, Singla N, Chander J. Occurence and phenotypic detection of class A carbapenemases among Escherichia coli and Klebsiella pneumoniae blood isolates at a tertiary care center. J Microbiol Immunol Infect 2013; 46(2): 104-8.

24. Tzouvelekis LS, Markogiannakis A, Psichogiou M, Tassios PT, Daikos GL. Carbapenemases in Klebsiella pneumoniae and other Enterobacteriaceae: an evolving crisis of global dimensions. Clin Microbiol Rev 2012; 25(4): 682-707. 